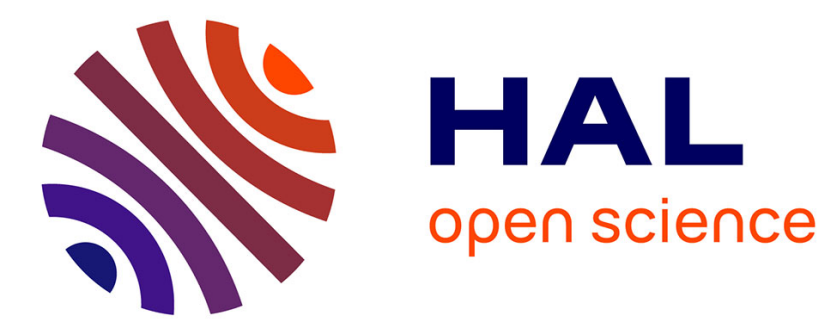

\title{
EXAFS Analysis of Co-Containing Polymers
}

J. Chaboy, C. Castro

\section{To cite this version:}

J. Chaboy, C. Castro. EXAFS Analysis of Co-Containing Polymers. Journal de Physique IV Proceedings, 1997, 7 (C2), pp.C2-1269-C2-1270. 10.1051/jp4:19972227 . jpa-00255301

\section{HAL Id: jpa-00255301 https://hal.science/jpa-00255301}

Submitted on 1 Jan 1997

HAL is a multi-disciplinary open access archive for the deposit and dissemination of scientific research documents, whether they are published or not. The documents may come from teaching and research institutions in France or abroad, or from public or private research centers.
L'archive ouverte pluridisciplinaire HAL, est destinée au dépôt et à la diffusion de documents scientifiques de niveau recherche, publiés ou non, émanant des établissements d'enseignement et de recherche français ou étrangers, des laboratoires publics ou privés. 


\title{
EXAFS Analysis of Co-Containing Polymers
}

\author{
J. Chaboy and C. Castro \\ Instituto de Ciencia de Materiales de Aragón \& Departamento de Física de la Materia Condensada, \\ CSIC-Universidad de Zaragoza, 50009 Zaragoza, Spain
}

\begin{abstract}
In this work we present a detailed analysis of the extended $x$-ray absorption fine structure (EXAFS) spectra at the cobalt $\mathrm{K}$-edge in a series of Co-containing polymers prepared by reaction of the Schiff-base polymer $\left(\mathrm{C}_{13} \mathrm{H}_{17} \mathrm{~N}_{3}\right)$ and a $\mathrm{CoX}_{2}$ salt, where $\mathrm{X}=\mathrm{NO}_{3}, \mathrm{ClO}_{4}, \mathrm{Cl}$ and $\left(\mathrm{SO}_{4}\right)_{1 / 2}$. The analysis of EXAFS data has confirmed the formation of polymericcoordination complexes as materials with a very low crystallinity.
\end{abstract}

\section{INTRODUCTION}

The search for molecular ferromagnetic matcrials has attracted a great deal of attention in the last years because their potential tcchnological applications. After the publication of the first works reporting the existence of organometallic compounds exhibiting ferromagnetic behavior, the possibility of preparing entirely organic-based ferromagnets has become a major challenge.

Mctallopolymers or coordination polymers have been sought out together with radical organic polymers as a type of magnetic polymers [1]. Metal incorporation to the polymers modifies the electrical, thermal and magnetic properties of this kind of materials, as it is the case of coordination polymers prepared from an organic polymer containing a recurring chelate group and treated with suitable metal salts to form the metal derivative[2]. The origin of their magnetic behavior may directly result from the the metal ion spins arranged as to be strongly coupled along the organic polymer backbone. However, some of these compounds have been reported to exhibit anomalous magnetic behavior and their chemical and magnetic characterization is a matter of controversy. This is the case of polymeric materials based on the tridentate Schiff-base polymer (P) formed from pyridine-2, 6-dialdehyde and hexamethylenediamine, and iron salts [3-5]. From the synthetic conditions one should expect a polymeric complex consisting of tridentate Schiff bases and hexacoordinated $\mathrm{Fe}$ (II) ions. As it is typical in related coordination compounds the iron would exhibit a low-spin $S=0$ configuration [6] and the material would be diamagnetic. However, the magnetic studies suggest the existence of net magnetic moments in the material, that can be originated by the modification of the ligand field through the deformation of the octahedral environment of Fe, or due to small particles of magnetic Fe(III) oxides built-in within polymer. Moreover, in the case of samples prepared with the organic polymer (P) and a suitable solution of $\mathrm{Co}$ (II) salt, also anomalous behavior has been reported [7] being the origin of their magnetic behavior not clear yet. Structural characterization is, therefore, a strong requirement to understand the origin of the magnetic properties of these materials, in particular to discern between the extrinsic or intrinsic nature of the obscrved anomalous magnetic behavior.

In this work we present the structural characterization of the local environment around cobalt in a series of Co-containing polymers prepared by reaction of the Schiff-base polymer $\left(\mathrm{C}_{13} \mathrm{H}_{17} \mathrm{~N}_{3}\right)$ and a $\mathrm{CoX} 2$ salt, where $\mathrm{X}=\mathrm{NO}_{3}, \mathrm{ClO} 4, \mathrm{Cl}$ and ( $\left.\mathrm{SO}_{4}\right)_{1 / 2}$. The Extended X-ray Absorption Fine Structure (EXAFS) region of the absorption spectra has been analyzed by means of ab-initio multiple-scattering calculations. Polymer coordination Schiff-base Co-containing complexes were prepared following synthetic methods described in the literature [7].

\section{RESULTS AND DISCUSSION}

In all the studied cases, the EXAFS signals indicate the low crystallinity of the systems. Indeed, the Fourier transforms do not exhibit contributions for interatomic distances larger than $4 \AA$. Moreover, the modulation of the EXAFS signals is very similar for the five polymer compounds and also resembles that of the monomer reference Co(M)I, although the intensity of the EXAFS structures is substantially reduced in the polymers compounds.

These results indicate both, the lower crystallinity of the polymers as compared with the monomer unit, and that the atomic environment of $\mathrm{Co}$ in the polymers is very close to that of the monomer reference. Hence, Co atoms should be surrounded by 6 nitrogen atoms arranged in octahedral geometry and by the $\mathrm{C}$ atoms of the tridentate quelate units.

To verify the reliability of this preliminary fingerprint analysis, and to determine how this environment is modified by the different $\mathrm{CoX}_{2}$ salts used in the synthesis procedure, we have performed a more detailed EXAFS analysis by using ab initio theoretical calculations at the Co.K-edge by applying the code EXCURV88, described elsewhere. The computation reproduces well the experimental spectra, indicating the reliability of the structural assumptions made. In all the polymer compounds investigated there is no trace of $\mathrm{Co}-\mathrm{Co}$ coordination and the local environment around $\mathrm{Co}$ is formed by six $\mathrm{N}$ atoms arranged in an octahedral layout as in the case of the monomer reference $\mathrm{Co}(\mathrm{M}) \mathrm{I}$. Moreover, nearest-neighbors present different distortions as a function of the nature of the counter-ion, $X$, of the different $C_{2} X_{2}$ salts used in the synthesis.

Special attention has been paid to the analysis of the $\mathrm{Co}(\mathrm{P}) \mathrm{Cl}-\mathrm{E}$ polymer compound. For this system two different Co structural environments have been proposed: $i$ ) as in the former polymers $\mathrm{Co}$ should be surrounded by $\mathrm{N}$ atoms in the first coordination shell; ii) the $\mathrm{Cl}$ atoms of the salt becomes coordinated to cobalt $[3,7]$. We have tested these two possibilities as shown in Fig. 1. The best-fits are found when two $\mathrm{Cl}$ and 3 nitrogen atoms are coordinated to the central $\mathrm{Co}$. On the contrary, the simulation performed by only including $\mathrm{N}$ atoms in the first-coordination sphere is rather unsatisfactory, showing strong differences, both in phase and intensity, between the experimental EXAFS signal and the theoretical one. 


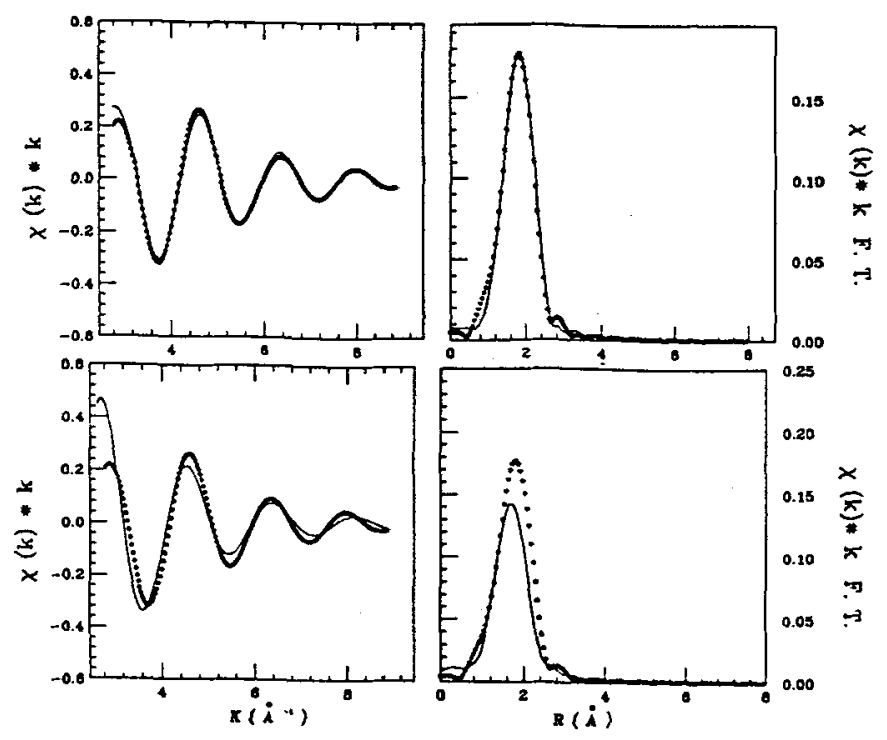

Figure 1: In the left panel, the k-weighted Fourier-filtered first-shell contribution of the experimental Co K-edge EXAFS spectrum of the $\mathrm{Co}(\mathrm{P}) \mathrm{Cl}-\mathrm{E}$ polymer is compared to the theorelical simulation ( solid line): i) nitrogen penta-coordination (bottom) and ii) $2 \mathrm{Cl}+3 \mathrm{~N}$ coordination ( top ).

The substances synthetized in aqueous medium, which are known as $\mathrm{Co}(\mathrm{P}) \mathrm{SO}_{4}, \mathrm{Co}(\mathrm{P}) \mathrm{NO}_{3}, \mathrm{Co}(\mathrm{P}) \mathrm{ClO} 4$ and $\mathrm{Co}(\mathrm{P}) \mathrm{Cl}$, have been revcaled as amorphous coordination polymers of ionic nature in which the cobalt ion is coordinated by 6 nitrogens atoms in a octahedral arrangement. The results for the two polymers obtained through synthetic modifications, $\mathrm{Co}(\mathrm{P}) \mathrm{SO} 4-\mathrm{C}$ and $\mathrm{Co}(\mathrm{P}) \mathrm{Cl}-\mathrm{E}$, are different each other. In the former similar ocuhedral environment around $\mathrm{Co}$ is found, whereas for $\mathrm{Co}(\mathrm{P}) \mathrm{Cl}-\mathrm{E}$ the $\mathrm{Cl}$ atoms of the salt becomes coordinated to Co.

In an octahedral crystal ficld, $\mathrm{Co}^{2+}$ presents a high-spin configuration $(\mathrm{S}=3 / 2)$ and the magnetic moment expected is $5.2 \mu_{\mathrm{B}}$ at room temperature, duc to the important orbital contribution of the ${ }^{4} \mathrm{~T} / \mathrm{g}$ ground state. Therefore, if cooperative interactions do not exist among magnetic cobalt ions these polymeric compounds should exhibit paramagnetic behavior throughout the temperature range, in contrast to the experimental observed behavior [5,7]. Two intrinsic mechanisms can be proposed to account for such anomalous magnetic behavior. The first one lies on the possibility to find a magnetic Co-Co interaction in the polymers. However, EXAFS analysis does not reveal any trace of $\mathrm{Co}-\mathrm{Co}$ coordination within the local environment around Co $(8 \AA)$. Secondly, the combined effect of crystalline distortions and spin-orbit coupling of the ${ }^{4} \mathrm{~T}_{1 \mathrm{~g}}$ level can led to a low-spin ( $S=1 / 2$ ) ground state close in energy to the first excited level, so that deviations from the normal paramagnetic behavior can be expected at high temperature [8-10], thus explaining the anomalous magnetic behavior found. However, the same anomalous bchavior is found in all these compounds despite EXAFS data address a different local structure around cobalt (from octahedral to penta-coordinated) induced upon modification of the solvent ( $\mathrm{Co}(\mathrm{P}) \mathrm{SO}_{4}-\mathrm{C}$ vs $\left.\mathrm{Co}(\mathrm{P}) \mathrm{Cl}-\mathrm{E}\right)$. Therefore, according to the present data both possibilities can be disregarded, in good agreement to recent results [7] addressing that the anomalous behavior observed is not intrinsic to the polymeric material but due to magnetic small particles .

Acknowledgments

This work was partially supported by CICYT Grant MAT93-0240C04. We wish also to acknowledge J. Garcia and F. Palacio for many friendly and fruitful discussions.

\section{References}

[1] J.S. Miller, Adv. Mater. 4 (1992) 435.

[2] F. Palacio, J. Ramos and C. Castro, Mol. Cryst. Liq. Cryst. 232 (1993)173.

[3] F. Lions and K.V. Martin, J. Am. Chem. Soc. 79 (1957) 2733.

[4] T. Sugano, M. Kinoshila , I. Shirotani and K. Ohno, Solid State Comm. 45 (1983) 99; T. Sugano, M. Nomura , K.

Agawa, P.H. Kieng, T. Ohta, M. Kinoshita and M. Bull, Chem. Soc. Jpn 59 (1986) 2615.

[5] F. Palacio, C. Castro, F.J. Lázaro and J. Reyes, J. Magn. Magn. Mater. 104 (1992) 2101.

[6] R.L. Carlin, Magnetochemistry (Springer-Verlag,1986).

[7] C. Castro, PhD Thesis, Zaragoza University (1994).

[8] K. Suetmatsu, K. Nakamura and J. Takeda , Polymer Journal 15 (1983) 71.

[9] MG. Ehrlich, F. R. Fronczek, S. F. Watkins, G.R. Newcome and D.C. Hager, Acta Crystall. Sect. C 40 (1984) 78.

[10] E.N. Maslen, C.L. Raston and A.H. White, J. Chem. Soc. Daiton Trans. 8 (1974) 1803. 